meinschaftliche Eigenschaften besitzen, dieselbe Constitution beanspruchen, ist eine noch weiter experimentell zu erledigende Frage.

\title{
XXIX.
}

\section{Ueber das im Krappspiritus enthaltene ätherische 0el.}

\section{Von}

F. Jeajean.

(Compt. rend. t. XLII. 1856. (No. 18.) p. 857.)

Seit einigen Jahren wird im südlichen Frankreich eine nicht unbedeutende Menge Alkohol durch Gährung der Krappwurzeln dargestellt. Derselbe besitzt aber einen sehr unangenehmen und ganz charakteristischen Geruch, weshalb ich unter der Leitung des Herrn Chancel in Montpellier eine Untersuchung der fremdartigen Beimischungen in solchem Alkohole unternahm, deren Resultate folgende sind:

Das mir zu Gebote stehende Fuselöl war zufällig durch Kupfersalze grün gefärbt, da es in kupfernen Gefässen gestanden hatte. Es war wenig dichter als Wasser und nach einiger Zeit bildeten sich darin Krystallfittern. Bei der Destillation giebt es bis zu $230^{\circ}$ flüssige Produkte; darüber hinaus erhitzt setzt sich im Retortenhalse eine feste weisse Masse ab. Unterbricht man zu der Zeit die Destillation, so füllt sich der Bauch der Retorte mit farnkrautähnlichen Krystallen.

Zu Folge der Angaben des in die kochende Flüssigkeit tauchenden Thermometers musste ich in den ersten Destillationsprodukten den Propion- und den Butylalkohol vermuthen, und das Verweilen des Thermometers bei $130^{\circ}$ machte den Amylalkohol wahrscheinlich. Die bei $130^{\circ}$ siedenden Produkte sind in viel grösserer Quantität als 
die vorhergehenden vorhanden, sie wurden durch Behandlung mit Kali und mit geschmolzenem Chlorcalcium gereinigt und dann der Analyse unterworfen, welche gleichfalls nachwies, dass sie aus Amylalkohol bestehen.

Die feste Substanz, welche während der Destillation sich bei $230^{\circ}$ ausschied, wurde zwischen Papier gepresst, mit sehr viel Wasser gewaschen und dann mehrmals aus Aether umkrystallisirt. Sie erschien dann als weisses Pulver, das einen pfefferartigen Geruch besitzt, der aber an denjenigen des gewöhnlichen Camphers erinnert.

Die Analyse lieterte folgende Zahlen:

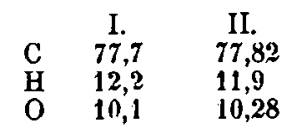

welche der Formel des Borneo-Camphers $=\mathrm{C}_{20} \mathrm{H}_{18} \mathrm{O}_{2}$ entsprechen.

Diese Substanz besitzt einen brennenden Geschmack und giebt bei der Sublimation Krystalle, welche sich unter dem Mikroskop als hexagonale Prismen zeigten. Auf eine kleine Quantität Wasser geworfen zeigte sie dieselbe drehende Bewegung wie Campher; sie ist wenig löslich in Wasser, sehr löslich aber in gewöhnlicher Essigsäure, so wie in Alkohol und Aether, woraus sie durch Wasser wieder niedergeschlagen wird. Bei der Destillation der Substanz über Zinkchlorür oder wasserfreier Phosphorsäure erhält man einen Kohlenwasserstoff, welcher in seinem Geruche an denjenigen des Citronen- und Bergamotöls erinnert. Sie verwandelt sich endlich durch kochende Salpetersäure in Laurineen-Campher, wie dies Pelouze an dem Campher der Dryobalanops camphora beobachtet hat.

Die Krystalle, welche sich im rohen Oel ausscheiden, besitzen alle Eigenschaften der so eben beschriebenen und durch Destillation erhaltenen Substanz. Ich glaube, dass ihre Bildung, wie die des festen Borneocamphers anderen Ursprungs, von der Hydratation eines in dem Oele enthaltenen Kohlenwasserstoffs abhängt. Zu seiner Isolirung behandelte ich die bei der ersten Destillation über 
$140^{\circ}$ übergegangene Flüssigkeit mit Kali, danu mit Chlorcalcium und destillirte sie darauf mehrmals, um sie von dem mit übergerissenen Campher zu befreien. Ich erhielt eine bei $160^{\circ}$ kochende Flüssigkeit vom Geruch des Krappöls.

Die Analyse dieser Flüssigkeit gab die Zahlen:

$$
\begin{array}{cr}
\text { C } & 88,23 \\
\text { H } & 11,81 \\
\hline 100,04
\end{array}
$$

Das spec. Gewicht ihres Dampfes ist 4,85; ihre Formel also $\mathrm{C}_{20} \mathrm{H}_{16}$, entsprechend 4 Vol. Dampf. Dieser Kohlenwasserstoff entspricht daher dem Borneen und ist wie dieser dem Terpentinöl isomer.

Noch wollte ich die Einwirkung beider Substanzen auf das polarisirte Licht studiren, leider reichte aber die Quantität des Kohlenwasserstoffs dazu nicht hin. Dagegen untersuchte ich das Verhalten des Camphers in dieser Beziehung und fand, dass er die Polarisationsebene nach Links dreht. Eine Auflösung von $20 \mathrm{Grm}$. Campher in $100 \mathrm{C}$. C. Alkohol gab eine Ablenkung von $\mathbf{1 2}^{\circ}$, woraus ich nach der von Biot gegebenen Formel schloss, dass das Rotationsvermögen dieses Camphers für eine Länge von 100 Millim.

$$
[a]=-34,5 \text {. }
$$

Es geben also die in der Krappwurzel enthaltenen zuckerartigen Bestandtheile durch die Gährung ausser dem gewöhnlichen Alkohol noch die höhern Alkohole, welche man gewöhnlich in dem Weinalkohole findet und diese Produkte enthalten ausser dem nach links drehenden Borneocampher noch besonders einen mit dem Terpentinöl isomeren Kohlenwasserstoff.

Dem fügt Biot folgende kurze Notiz bei:

Es scheint ihm der Schluss von der Identität der festen Substanz im Krappalkohol mit Pelouze's Borneocampher vollkommen berechtigt. Chemische Zusammensetzung, Richtung und Grösse der Drehung der Polarisationsebene, die Fähigkeit, sich in Laurineencampher um- 
zuwandeln, nachdem die Substanz 2 Aequiv. Wasserstoff verloren hat, alle diese Eigenschaften haben beide Substanzen gemein.

Bei Untersuchung des Drehungsvermögens des durch Salpetersäure erhaltenen Laurineen-Camphers und Vergleichung desselben mit dem des gewöhnlichen Camphers ergeben sich folgende Thatsachen:

Es wurden zunächst 12 Grm. aus Krappspiritus erhaltener Borneocampher mit Salpetersäure behandelt und dann $10 \mathrm{Grm}$. des erhaltenen Produkts in $50 \mathrm{c}$. C. Alkohol aufgelöst. Bei Beobachtung dieser Lösung in polarisirtem Lichte fand ich als Mittel aus 5 gut übereinstimmenden Versuchen:

$$
\alpha=-47,3 \text {. }
$$

also eine mit dem des Laurineencamphers gleiche, aber entgegengesetzte Drehung. Eine Mischung gleicher Volumina gleich titrirter Lösungen von diesem und von Laurineencampher zeigte keine Drehung der Polarisationsebene.

Es existiren also, wie aus diesen und früheren Mittheilungen folgt, 2 neue parallele Reihen isomerer Körper, welche gleiches aber entgegengesetztes Drehungsvermögen besitzen.

\begin{tabular}{l|l}
$\begin{array}{l}\text { Rechts. } \\
\text { Borneocampher aus Dryo- } \\
\text { balanops Camphora. }\end{array}$ & $\begin{array}{c}\text { Links. } \\
\text { Durch Salpetersäure daraus } \\
\text { spiritus. } \\
\text { gebildeter gewöhnlicherCam- } \\
\text { pher. }\end{array}$ \\
$\begin{array}{l}\text { Camphersäure. } \\
\text { Debildeter Salpetersäure daraus }\end{array}$ \\
pher. \\
Camphersäure.
\end{tabular}

